DOI: https://doi.org/10.24867/09GI10Horvat

\title{
PRIMENA SOFTVERSKIH REŠENJA U PROIZVODNIM PREDUZEĆIMA NA TERITORIJI REPUBLIKE SRBIJE
}

\section{APPLICATION OF SOFTWARE SOLUTIONS IN MANUFACTURING COMPANIES IN THE TERRITORY OF THE REPUBLIC OF SERBIA}

\section{Mina Horvat, Fakultet tehničkih nauka, Novi Sad}

\begin{abstract}
Oblast: INŽENJERSKI MENADŽMENT
Kratak sadržaj - Predmet istraživanja u okviru rada obuhvata primenu softverskih rě̌enja u proizvodnim preduzećima na teritoriji Republike Srbije, istraživanjem su obuhvaćena 74 preduzeća iz proizvodnog sektora, od konditorske, preko tekstilne $i$ hemijske industrije do industrije metala. Da bi se mogla sprovesti statistička analiza, uzorak je podeljen na 4 subuzorka na osnovu kriterijumskog obeležja povrat od prodaje preduzeća, $i$ to: negativan $i$ od 0 do 2\%; od 2 do 5\%; od 5 do 10\%, $i$ preko $10 \%$.
\end{abstract}

Ključne reči: informacione tehnologije, proizvodne kompanije, istraživanje

Abstract - The subject of research within the paper includes the application of software solutions in manufacturing companies in the territory of the Republic of Serbia, the research covers 74 companies from the manufacturing sector, from confectionery, through textile and chemical industry to the metal industry. In order to be able to conduct a statistical analysis, the sample was divided into 4 subsamples based on the criterion of return on sales of the company, as follows: negative and from 0 to $2 \%$; from 2 to $5 \%$; from 5 to $10 \%$, and over $10 \%$.

Keywords: information technology, manufacturing companies, research

\section{UVOD}

Kompanije teže da rade brže i bolje, da sa što manje resursa postignu više, da povećaju nivo produktivnosti, efektivnost, efikasnost, koje će im omogućiti veliki uspeh. I baš na tom putu, informacioni sistemi dobijaju sve veću ulogu i više pažnje. Najčešće prednosti informacionih sistema su da komunikacija postaje brža i efikasnija, moguće je čuvanje velikog broja podataka na malom prostoru, povećava se produktivnost zaposlenih, mogućnost analize velikog broja podataka, a zatim i zaključivanje na osnovu njih. Takođe, postiže se automatizacija poslovnih procesa, finansijska isplativost i olakšana dostupnost. Zbog toga, predmet istraživanja u okviru rada obuhvata primenu softverskih rešenja u proizvodnim preduzećima, kojim su obuhvaćena 74 preduzeća. Da bi se mogla sprovesti statistička analiza, uzorak je podeljen na 4 subuzorka na osnovu kriterijumskog obeležja povrat od prodaje preduzeća - negativan i od 0 do $2 \%$, od 2 do $5 \%$, od 5 do $10 \%$, i preko $10 \%$.

\section{NAPOMENA:}

Ovaj rad proistekao je iz master rada čiji mentor je bio prof. dr Bojan Lalić.
Ključni problem, kao i celokupna problemska orijentacija ovog istraživanja, vezuje se za analizu deset tematskih celina: celina $C_{1}$ - mišljenje preduzeća o uspešnosti njihovog preduzeća u odnosu na konkurenciju, celina $\mathrm{C}_{2}$ - vrsta industrije kojoj preduzeća pripadaju, celina $\mathrm{C}_{3}$ - broj zaposlenih u preduzeću, celina $\mathrm{C}_{4}$ - mišljenje preduzeća o konkurentskim faktorima prema značaju, u odnosu na konkurenciju, celina $C_{5}$ - mišljenje preduzeća o uticaju konkurencije, celina $\mathrm{C}_{6}$ - mišljenje preduzeća o važnosti softvera (office, softveri za komunikaciju i ERP softveri), celina $\mathrm{C}_{7}$ - mišljenje preduzeća o važnosti specijalizovanih softvera, celina $\mathrm{C}_{8}$ - mišljenje preduzeća o učestalom korišćenju softvera (office, softveri za komunikaciju i ERP softveri), celina $C_{9}$ - mišljenje preduzeća o učestalom korišćenju specijalizovanih softvera $\mathrm{i}$ celina $\mathrm{C}_{10}-$ mišljenje preduzeća o mogućim preprekama koje utiču na uvođenje softvera, u odnosu na povrat od prodaje.

Uzimajući u obzir osnovu problema, predmeta i ciljeva istraživanja, kao i metodološki pristup u ovom istraživanju, postavljena je osnovna hipoteza: $\mathrm{H}_{0}-\mathrm{Ne}$ postoji značajna razlika između subuzoraka po posmatranim tematskim celinama. Ukoliko se ne dokažu postupci o postojanju sličnosti subuzoraka, time se ukazuje na postojanje razlika i prihvata se alternativna hipoteza: $\mathrm{A}_{0}$ Postoje značajne razlike između subuzoraka po nekim posmatranim tematskim celinama.

\section{INFORMACIONI SISTEMI}

Informacioni sistem je sistem koji prikuplja, skladišti, obrađuje $\mathrm{i}$ isporučuje informacije relevantne za poslovna preduzeća, tako da su informacije dostupne i upotrebljive svima koji ih koriste. [1]

Osnovni cilj svakog informacionog sistema je da prikuplja, obrađuje i na taj način proizvodi potrebne informacije za upravljanje sistemom. Kako bi proces tekao nesmetano, informacioni sistem mora biti efikasan $\mathrm{i}$ na racionalan način treba da vrši razmenu informacija o osnovnim ciljevima, zadacima, stanju pojedinih komponenti i o procesu kako bi krajnji korisnik bio zadovoljan.

\section{KOMPONENTE INFORMACIONIH SISTEMA}

Osnovne komponente informacionih sistema su:

- hardver,

- softver,

- baze podataka,

- telekomunikacijski sistemi i tehnologije, i

- ljudski resursi i procedure. [2] 


\section{KLASIFIKACIJA INFORMACIONIH SISTEMA}

Informacioni sistemi se mogu klasifikovati prema organizacionoj strukturi, glavnim funkcionalnim oblastima, podršci koju pružaju i arhitekturi.

Informacioni sistemi se mogu grupisati u odnosu na područje koje obuhvataju, broj ulaznih i izlaznih informacija, načinu realizacije procesa pripreme i obrade podataka, stepenu automatizacije procesa informacionih sistema. [3]

\section{PREDNOSTI I NEDOSTACI SOFTVERA U POSLOVANJU}

Najčešće prednosti i mane informacionih sistema:

Prednosti informacionih sistema - komunikacija; čuvanje velike količine informacija na malom prostoru; globalizacija; brzo i efikasno tumačenje velikih količina podataka; povećana produktivnost dostupnost; automatizacija poslovnih procesa i manuelnih zadataka; višestruka iskorišćenost, finansijska isplativost.

Mane informacionih sistema - kompleksni softveri; veći troškovi razvoja softverskog sistema; održavanje softvera; sužavanje individualnih znanja; troškovi implementacije; sigurnost. [4]

\section{ISTRAŽIVAČKI DEO RADA}

Upitnik je formiran u elektronskoj formi, za ovaj vid je odlučeno zbog praktičnih razloga, bržeg distribuiranja, lakšeg prikupljanja.

Veći deo ispitanika iz uzorka čine vlasnici ili direktori preduzeća, dok su pojedini ispitanici direktori različitih sektora u okviru preduzeća (marketinga, prodaje i finansija). Ispitanici su imali mogućnost da ostanu anonimni.

Istraživanje je sprovedeno tokom novembra meseca, 2019. godine. Istraživački deo je obuhvatio ispitanike iz 74 preduzeća koja spadaju u proizvodni sektor (proizvodnja metala i mašinski rad; proizvodnja računarskih, elektronskih i optičkih proizvoda i rashladni uređaji; prehrambena industrija i industrija pića; tekstilna industrija; drvna industrija i industrija nameštaja; hemijska industrija, biotehnologija i farmaceutska industrija; duvanska industrija, industrija nafte i gasa, industrija sportske opreme; industrija gume, plastike i ambalaže; industrija građevinskih materijala, industrija keramike i automobilska industrija).

\subsection{Hipoteze istraživanja}

Uzimajući u obzir osnovu problema, predmeta i ciljeva istraživanja, kao i metodološki pristup $u$ ovom istraživanju, može se postaviti osnovna hipoteza:

$\mathrm{H}_{0}$ - Ne postoje značajne razlike između subuzoraka po posmatranim tematskim celinama, i $\mathrm{A}_{0}$ - Postoje značajne razlike između nekih subuzoraka po posmatranim tematskim celinama.

Postupkom MANOVA se testira hipoteza $\mathrm{H}_{1}$ koja glasi:

$\mathrm{H}_{1}$ - Ne postoje značajne razlike između subuzoraka po posmatranim tematskim celinama na osnovu pojedinačnih obeležja, i A1 - Postoje značajne razlike između nekih subuzoraka po posmatranim tematskim celinama na osnovu pojedinačnih obeležja.
Postupkom diskriminativne analize testira se hipoteza $\mathrm{H}_{2}$ : $\mathrm{H}_{2}$ - Ne postoji jasno definisana granica između subuzoraka za posmatranu tematsku celinu gledajući sva obeležja ukupno, i $\mathrm{A}_{2}$ - Postoji jasno definisana granica između nekih subuzoraka za posmatranu tematsku celinu gledajući sva obeležja ukupno.

Postupkom ANOVA ili Roy-evog testa se testira hipoteza $\mathrm{H}_{3}: \mathrm{H}_{3}-\mathrm{Ne}$ postoji značajna razlika između subuzoraka po pojedinim obeležjima, i $A_{3}$ - Postoji značajna razlika između nekih subuzoraka po pojedinim obeležjima.

\section{DISKUSIJA ISTRAŽIVAČKOG DELA}

Analiza mišljenje preduzeća o uspešnosti njihovog preduzeća u odnosu na konkurenciju u odnosu na povrat od prodaje

Za preduzeća koja imaju negativan ili od 0 do $2 \%$ povrata od prodaje, proizvodni troškovi bez plata zaposlenih, pouzdanost $\mathrm{u}$ isporuci, kvalitet proizvoda ne prestavljaju im značajan faktor, odnosno lošiji su u poređenju sa konkurencijom. Sposobnosti prilagođavanja proizvodne količine i proizvoda i sposobnosti zadovoljavanja klijenata izražavaju sa srednjom zadovoljnošću. Kako raste profitabilnost, tako raste i odgovornost i zadovoljavanje potreba klijenata, parametri sa odgovorima lošije ili srednje, zamenjuju se sa bolje i mnogo bolje. Preduzeća sa većim povratom od prodaje više ulažu u kvalitet proizvoda, pouzdanost isporuke, prilagođavanje kupcima i inovativnošću proizvoda.

Analiza važnosti specijalizovanih softvera u odnosu na povrat od prodaje

Preduzeća sa veoma malim povratom od prodaje, najveću važnost vide u PLM i FEM softverima, modeliranju poslovnih procesa, CAE i PDM softverima, dok softveri za istraživanje tržišta i digitalne platforme ne predstavljaju važnost u njihovom poslovanju. Internet trgovina i PDM softveri predstavljaju najveću važnost za preduzeća sa povratom od prodaje od 2 do $5 \%$, dok sistemi poslovne inteligencije, FEM i CAM softveri ne predstavljaju važnost. Kako raste povrat od prodaje, tako raste svest za primenom softvera u preduzećima, preduzeća bi više ulagala, jer smatraju da im to olakšava poslovanje, povećava efektivnost, efikasnost, preciznost podataka, ubrzava procese. Softveri za CAD, CAE, simulacije i proračune su veoma značajni za preduzeća sa profitabilnošću preko $10 \%$. Takođe, pojedini softveri su primenljivi bez obzira na povrat od prodaje i preduzeća bi ulagale novac u njih, kao što su PDM, CAE, modeliranje poslovnih procesa, socijalne mreže i CAD.

Analiza mogućih prepreka koje utiču na uvođenje softvera u odnosu na povrat od prodaje

Na preduzeća sa negativnom ili od 0 do $2 \%$ povratom od prodaje pokazan je veoma značajan uticaj na parametre: nedostataka kvalifikovanih zaposlenih, visokih troškova kupovine i visokih troškova obuke radnika. Prosečan uticaj za parametre: nevidljiv direktan benefit, neintegracija sa ostalim softverima $\mathrm{i}$ visoki troškovi kupovine novih softvera su pokazani kao odlika preduzeća sa povratom od prodaje 5 do $10 \%$. Preduzeća sa povratom od prodaje većom od $10 \%$ smatraju da nevidljiv direktan benefit $\mathrm{i}$ internet nebezbednost ne predstavljaju nikakav faktor prilikom uvođenje softvera, dok nedostatak kvalifikovanih 
zaposlenih i visoki troškovi kupovine novih softvera imaju značajan uticaj.

\section{Analiza korišćenja specijalizovanih softvera u odnosu na povrat od prodaje}

Preduzeća sa velikim povratom od prodaje koriste softvere koji im mogu pomoći i olakšati poslovanje, jedni od tih grupa su sistemi poslovne inteligencije, PLM, internet trgovina, CAE, socijalne mreže, FEM, modeliranje poslovnih procesa.

Sa druge strane, preduzeća koja imaju izuzetno mali povrat od prodaje deo svog kapitala ulažu u softvere za modeliranje poslovnih procesa, FEM, PLM, dok ni u kojem slučaju svoj novac ne investiraju u upitnike za dobijanje feedback-a od klijenata, socijalne mreže, internet stvari.

Zanimljiv podatak jeste da softveri za modeliranje poslovnih procesa i FEM softveri, preduzeća koriste ili u većem delu ili nimalo, na to utiče vrste industrije iz koje preduzeća dolaze. Takođe, zanimljiv podatak jeste da preduzeća koja imaju povrat od prodaje između 2 i $5 \%$ u većem delu, uopšte ne koriste softvere, osim izuzetaka za internet trgovinu i vebsajta preduzeća.

\section{Analiza korišćenja softvera - office, za komunikaciju i ERP softveri u odnosu na povrat od prodaje}

Preduzeća sa najmanjim povratom od prodaje $u$ potpunosti koriste email i softvere za rad sa tabelama, dok manjim delom softvere za prodaju i CRM. Veliku ulogu imaju softveri za rad sa tabelama i email, pošto oni predstavljaju najjeftinije softvere za pomoć prilikom rada, logično je zašto se preduzeća u početku svog rada ili kada nisu u tolikoj finansijskom mogućnosti odlučuju za njih.

Softvere za ljudske resurse, email, rad sa tabelama i softvere za planiranje proizvodnje u potpunosti koriste preduzeća sa povratom od prodaje od 2 do $5 \%$.

Karakteristično za preduzeća sa povratom od prodaje većim od $10 \%$ jeste da većim delom koriste softvere za finansije i računovodstvo i za planiranje proizvodnje.

\section{Analiza konkurentskih faktora prema značaju u odnosu na povrat od prodaje}

Preduzeća sa malim povratom od prodaje, najviše obraćaju pažnju na cenu proizvoda, kako bi se prilagodili kupcima. Ne obraćaju toliku pažnju na kvalitet i inovativnost proizvoda, razvoj im ne predstavlja prioritet, odnosno nemaju sredstva za ulaganje. Odnos sa kupcima im je od velikog značaja, kako bi mogli proširiti svoje poslovanje i smatraju da je to jedan od najvažnijih faktora.

Preduzeća koje prelaze u blagi plus, počinju da razmišljaju o inovativnosti proizvoda i da zarađeni novac ulažu. Kvalitet proizvoda i cena su im veoma značajni, ali ipak postoje preduzeća kojima je kvalitet na zadnjem mestu. Ne obraćaju veliku pažnju na usluge i isporuku robe. Preduzeća koja imaju povrat od prodaje od 5 do $10 \%$, najviše obraćaju pažnju i smatraju svojom konkurentnošću - inovativnost proizvoda. Dok svi ostali parametri ne predstavljaju veliku važnost, odnosno važnost je raspodeljena između preduzeća. Fokus za preduzeća sa povratom od prodaje iznad $10 \%$ jeste cene proizvoda i kvalitet, dok isporuka na vreme i usluge ne predstavljaju značajan faktor.

\section{Analiza važnosti softvera - office, za komunikaciju i ERP softveri u odnosu na povrat od prodaje}

Preduzeća koja imaju veći povrat od prodaje shvataju važnost uvođenja softvera za prodaju i CRM, takođe, za produktivnost sastanaka, konferencija, kao i softvera koji služe kao određene baze podataka za slanje poruka. Preduzeća sa preko $10 \%$ povrata od prodaje bi ulagali u softvere za finansije i računovodstvo i ljudske resurse. Dok preduzeća sa negativnim ili veoma malim povratom od prodaje, skoro nikad ne bi ulagala novac u softvere za finansije i računovodstvo.

\section{Analiza uticaja konkurencije u odnosu na povrat od prodaje}

Kako raste povrat od prodaje, tako raste i pritisak pod kojim su preduzeća od strane konkurencije. Preduzeća koji imaju negativan ili 0 do $2 \%$ povrata od prodaje, smatraju da oni nisu pod velikim uticajem konkurencije, ali smatraju takođe da se nalaze u visoko konkurentnom društvu. Dok za preduzeća sa povratom od prodaje preko $10 \%$, smatraju da su pod velikim pritiskom od strane konkurencije. Kako pritisak raste, sa povećanjem povrata od prodaje, tako obraćanje pažnje na konkurenciju opada, pa tako preduzeća koji imaju negativan ili 0 do $2 \%$ povrata od prodaje obraćaju veliku pažnju na konkurenciju, dok preduzeća sa preko $10 \%$ profitabilnosti, ni ne obraćaju pažnju.

\section{Analiza vrste industrije kojoj preduzeća pripadaju u odnosu na povrat od prodaje}

Jedina karakteristika koja se ispoljila za vrstu industrije, jeste za prehrambenu industriju i industriju pića, kao i za industriju gume i plastike i ambalaža. Te industrije su se pokazale sa najmanjim povratom od prodaje, odnosno 0 do $2 \%$. Na osnovu analiza, shvaćeno je da vrsta industrije ne predstavlja važnu ulogu i nije ključni parametar $u$ istraživanju.

\section{Analiza broj zaposlenih u preduzećima u odnosu na povrat od prodaje}

Broj zaposlenih u preduzećima ne predstavlja veliki značaj u poslovanju. Prema istraživanju, pronašle su se jedino karakteristike da preduzeća koja posluju negativno, od 0 do $2 \%$ i preduzeća sa 5 do $10 \%$, imaju broj zaposlenih od 10 do 49. Pošto sam doprinos ove celine nije velik, ona ne predstavlja značajan faktor u istraživanju i na osnovu ove celine ne mogu se doneti precizni zaključci.

\section{ZAKLJUČAK}

Preduzeća sa negativnom ili od 0 do $2 \%$ povratom od prodaje karakterišu, proizvodni troškovi bez plata zaposlenih, pouzdanost $\mathrm{u}$ isporuci i kvalitet proizvoda, ti faktori im ne prestavljaju značajnost, ili su veoma skupi da bi mogli da im se posvete. Preduzeća se ne odlučuju da investiraju svoj novac u uvođenje novih softvera zbog nedostataka kvalifikovanih zaposlenih, visokih troškova kupovine novih softvera, visokih troškova obuke radnika, teškoće prelaska sa starog softvera, neprihvatanje promena od strane radnika, kao i nevidljivog direktnog benefita. U najvećoj meri preduzeća nemaju sredstava za inovacije, te ih to sprečava $u$ uvođenju kvalitetnih i neophodnih softvera. U preduzećima gde je profitabilnost niža, veliku ulogu imaju softveri za rad sa tabelama, 
email, kako oni predstavljaju najjeftinije softvere za pomoć prilikom rada, nije čudno zašto se preduzeća u početku svog rada ili kada nisu u tolikoj finansijskom mogućnosti, odlučuju za njih. Preduzećima sa malim povratom od prodaje najviše je stalo, odnosno najviše obraćaju pažnju na cenu proizvoda, da bi se prilagodili kupcima. Ne obraća se tolika pažnja na kvalitet i inovativnost, razvoj ne predstavlja prioritet, pošto $u$ najvećem broju slučaja nemaju sredstava za njega. Za preduzeća sa niskom profitabilnošću veoma je značajno da prodaju proizvod, kako bi mogli opstati, zato potenciraju na dobrim odnosima sa kupcima. U odnosu na konkurenciju preduzeća ističu svoju cenu proizvoda, prilagođavanje zahtevima kupaca, dok pojedini izdvajaju i svoje usluge. Preduzeća obraćaju veliku pažnju na svoju konkurenciju i smatraju da se nalaze $u$ visoko konkurentskoj industriji.

Preduzeća sa povratom od prodaje od 2 do $5 \%$ obraćaju pažnju na proizvodne troškove bez plata zaposlenih, sposobnost prilagođavanja isporuka, dok kvalitet proizvoda zavisi od preduzeća do preduzeća, nekim je veoma značajan, dok druga preduzeća ne obraćaju veliku pažnju na to. Preduzeća smatraju da veliku važnost u poslovanju predstavljaju softveri za socijalne mreže, internet trgovina, PDM softveri, softveri za modeliranje poslovnih procesa i CAE softveri zavise od grane industrije kojoj preduzeća pripadaju. Najviše korišćeni softveri su za ljudske resurse, email, softveri za rad sa tabelama i za planiranje proizvodnje. U odnosu na konkurenciju preduzeća ističu svoju inovativnost proizvoda, cenu, dok neka preduzeća ističu i kvalitet proizvoda. Zbog nevidljivog direktnog benefita i visokih troškova kupovine novih softvera, preduzeća se najčešće odlučuju da ne ulažu u nove softvere, takođe oni smatraju da se nalaze pod velikim pritiskom od strane konkurencije.

Preduzeća sa povratom od prodaje od 5 do $10 \%$, najčešće se odlučuju da ne uvode softvere zbog nevidljivog direktnog benefita, internet (ne)bezbednost, ne integracije sa ostalim softverima i kod visokih troškova kupovine novih softvera. Obraćaju veliku pažnju na pouzdanost u isporuci i na kvalitet proizvoda, u odnosu na konkurenciju, preduzeća ističu svoju inovativnost proizvoda. Preduzeća smatraju da veliku važnost u poslovanju predstavljaju softveri za socijalne mreže, CAE softver, softveri za prodaju i CRM i email, dok najviše koriste email.

Preduzeća sa povratom od prodaje većim od $10 \%$ karakteriše odlučnost da sredstva ulažu u softvere za $\mathrm{CAD}, \mathrm{CAE}$, simulacije i proračune, sisteme poslovne inteligencije, PLM, internet trgovinu, socijalne mreže, FEM, modeliranje poslovnih procesa, softvere za prodaju i CRM, finansije i računovodstvo, planiranje proizvodnje i email. Nevidljiv direktan benefit $i$ internet (ne)bezbednost ne predstavljaju nikakav uticaj za preduzeća da ne bi uvodili softvere, dok nedostatak kvalifikovanih zaposlenih i visoki troškovi kupovine novih softvera predstavljaju značajan uticaj zašto se preduzeća ipak odlučuju da ne investiraju svoj novac.
Preduzeća obraćaju veliku pažnju na inovativnost proizvoda, sposobnost prilagođavanja proizvodne količine i na proizvodne troškove bez plata zaposlenih i na kvalitet proizvoda. U odnosu na konkurenciju, preduzeća ističu svoju prednost kroz cenu proizvoda i njegov kvalitet, dok smatraju da se nalaze pod velikim pritiskom od strane konkurencije.

Nije dokazana veza između profitabilnosti firme, vrste industrije i korišćenja softvera, uzorak po industrijama nije bio dovoljan da bi se pokazala veza. Profitabilnost ne zavisi od korišćenja softvera u različitim veličinama preduzeća.

Preduzeća ne shvataju u velikoj meri važnost vebsajta, upitnika za feedback od klijenata i istraživanje tržišta, softvera za sisteme poslovne inteligencije. Preduzeća sa većim povratom od prodaje više ulažu u kvalitet proizvoda, pouzdanosti u isporuci, prilagođavanju prema kupcima, a samim tim i inovativnošću proizvoda. Takođe, kako raste profitabilnost tako raste i svest za primenom softvera u preduzećima, preduzeća bi više ulagala sredstva, jer smatraju da im to olakšava poslovanje, povećava efektivnost, efikasnost, preciznost podataka, ubrzava procese.

Može se zaključiti da postoji jasna granica i razlika između grupa preduzeća. Samim tim, hipoteza $\mathrm{H}_{0}$ - ne postoje značajne razlike između subuzoraka po posmatranim tematskim celinama, može da se odbaci i prihvata se alternativna hipoteza $\mathrm{A}_{0}$ - postoje značajne razlike između subuzoraka po posmatranim tematskim celinama.

\section{LITERATURA}

[1] Buckingham, R. (1987). Information Systems Education: Recommendations and Implementation. Cambridge University Press.

[2] Bečejski - Vujaklija, D. (2008). Uvod u informacione sisteme. Beograd: FON.

[3] Đurdić, D. B., Ćosić, D. D., \& Todorović, M. M.

(n.d.). Uvod u informacione sisteme. Beograd.

[4] Muhsinzoda, M. (2015, Decembar 6). Advantages and disadvantages of information systems. Preuzeto sa

Duesto: https://blogs.deusto.es/masterinformatica/advantages-and-disadvantages-ofinformation-systems/

\section{Kratka biografija:}

Mina Horvat rođena je u Novom Sadu 1995. godine. Diplomirala je na Fakultetu tehničkih nauka iz oblasti Inženjerskog menadžmenta - projektni menadžment 2018. godine. Iste godine upisuje master studije na Fakultetu tehničkih nauka smer Inženjerski menadžment - projektni menadžment. U toku studija bila je član Marketing tima Fakulteta tehničkih nauka i volontirala u više preduzeća. 